\title{
CULTURA SURDA E ASTRONOMIA: Investigando as Potencialidades Dessa Articulação para o Ensino de FÍsica
}

\author{
Ellen Cristine Prestes Vivian ${ }^{1}$ \\ André Ary Leonel²
}

\begin{abstract}
RESUMO
Este trabalho apresenta uma investigação acerca da potencialidade do tema Astronomia em Língua Brasileira de Sinais (Libras) aliada às Tecnologias Digitais da Informação e Comunicação (TDICs) no processo de ensino-aprendizagem de Física para surdos. Para contribuir com a pesquisa, elaboramos um minicurso em Língua Brasileira de Sinais (Libras), considerando o uso de TDICs. Ofertamos esse minicurso durante a Semana Acadêmica Integrada da Universidade Federal do Pampa. Como instrumento de análise, construímos e utilizamos um questionário on-line para ser respondido pelos participantes após o minicurso. A abordagem foi de cunho qualitativo, com viés na análise de conteúdo. Concluímos que o conhecimento da Libras e da Cultura Surda são indispensáveis para o planejamento de estratégias de ensino-aprendizagem e para a inclusão e a permanência dos sujeitos surdos na escola. Quanto à abordagem de Astronomia, podemos afirmar que recursos didáticometodológicos visuais, criação de sinais na área, bem como o apoio de TDIC com uso de softwares, favorecem o processo de ensino-aprendizagem, despertando o interesse dos envolvidos e possibilitando maior compreensão acerca desta temática. A articulação entre Astronomia em Libras e a integração das TDIC para a cultura surda, incorporadas à atuação dos educadores, proporcionam potenciais contribuições na educação de surdos.
\end{abstract}

Palavras-chave: Libras. Ensino de física. Astronomia. TDIC.

DEAF CULTURE AND ASTRONOMY:

INVESTIGATING THE POTENTIAL OF THIS ARTICULATION FOR THE TEACHING OF PHYSICS

\begin{abstract}
This work presents an investigation into the potentiality of the theme: Astronomy in Brazilian Sign Language (Libras) allied with Digital Information and Communication Technologies (DICT) in the teaching-learning process of Physics for the deaf. As a contribution to the analysis, we developed a short course in Brazilian Sign Language (Libras), with the use of DICT. The short course was given during the Federal University of Pampa's Integrated Academic Week. An online questionnaire was developed to be answered by the participants following the short course. The approach was qualitative, directed towards content analysis. The conclusion highlights that the knowledge of Libras and Deaf Culture are indispensable for the planning of teaching-learning strategies and for the inclusion and permanence of deaf individuals in school. On the subject of astronomy, visual didactic-methodological resources, the creation of signs for the area, as well as the support of DICT with the use of software demonstrated to be favorable to the teaching-learning process, arousing the interest of those involved and allowing greater understanding on this subject. Linking Astronomy in Libras to the integration of DICT for deaf culture, in addition to the role of educators, provides potential contributions to the education of the deaf.

Keywords: Libras. Teaching physics. Astronomy. DICT.
\end{abstract}

RECEBIDO EM: 15/12/2017

ACEITO EM: 2/7/2018

\footnotetext{
Professora Intérprete de Libras. Mestranda do Programa de Pós-Graduação em Educação Matemática e Ensino de Física, área de Ensino de Física. http://lattes.cnpq.br/1848443305816140. Orcid: https://orcid.org/0000-0002-5181-507X. ellencristinevmmb@hotmail.com

2 Licenciado em Física (2004). Mestre (2010) e doutor (2015) em Educação Cientifica e Tecnológica pela Universidade Federal de Santa Catarina. Professor-adjunto no Departamento de Metodologia de Ensino desta mesma instituição. Participa do grupo de pesquisa Comunic da UFSC. Orientador no Programa de Pós-Graduação em Educação Matemática e Ensino de Física da Universidade Federal de Santa Maria. Tem experiência na área de Física, com ênfase em Ensino de Física e na formação de professores, atuando principalmente nos seguintes temas: tecnologias digitais da informação e comunicação, alfabetização científica e técnica e física moderna e contemporânea. http://lattes. cnpq.br/6703447252635796. Orcid: https://orcid.org/0000-0002-6875-8876.profandrefsc@yahoo.com.br
} 


\section{CONSIDERAÇÕES INICIAIS: O Sujeito Surdo e o Papel da Astronomia na Educação}

A cultura surda passou por diversos marcos históricos com a imposição de uma cultura dominante (STROBEL, 2016) e oralista. Para Perlin (2004), a imposição do oralismo constituiu-se como uma violação da cultura do povo surdo. O surdo necessita adquirir primeiramente sua língua natural ou materna, que é a língua de sinais e, posteriormente, a língua oficial do seu país, constituindo, nesse sentido, o bilinguismo (GOLDFELD, 1997).

Desses marcos históricos sociais na educação dos surdos, até recentes conquistas asseguradas pelas lutas das comunidades surdas, temos muitos avanços, principalmente nos aspectos legais.

Com essas lutas percebe-se que a presença de alunos surdos nas classes regulares é uma realidade comum na sociedade atual, demandando o planejamento e investimento em estratégias didático-metodológicas que garantam a inclusão, tanto no ambiente escolar quanto na sociedade, e a qualidade na educação destes sujeitos.

Quanto ao ensino de Física, por ser considerada uma das disciplinas mais difíceis pelos estudantes, cria-se um obstáculo ainda maior no contexto inclusivo, que deveria ser tido como bilíngue. Isso porque, em muitos casos, o professor que leciona a disciplina não tem conhecimento da cultura surda e o Intérprete de Libras não possui domínio dos conteúdos específicos da disciplina. Além disso, de modo geral, os alunos surdos também desconhecem a própria língua natural, pelo convívio familiar com maioria ouvintes em espaços oralistas.

Essas questões configuram-se em uma barreira comunicativa que interfere negativamente no processo de ensino-aprendizagem dos sujeitos envolvidos. Esse cenário diferencia-se quando o sujeito surdo é proveniente de uma família surda, ou quando o mesmo participa e frequenta escolas e ambientes bilíngues.

É importante destacar que, para se compreender o processo de ensino-aprendizagem, em uma concepção gestual e visual, o professor necessita reconhecer os aspectos linguísticos e culturais desses alunos, e convêm ao intérprete introduzir-se no estudo sobre os conceitos e definições científicas. Para que isso se efetive é indispensável que haja tempo específico para planejamento, reservado a ambos os profissionais.

Como os sujeitos surdos experimentam o mundo pelas suas experiências visuais, uma das áreas científicas com grandes potenciais, no viés de favorecer esse fator, é a Astronomia. A Astronomia está presente nas nossas vidas a todo instante, desde uma simples observação noturna sob o céu estrelado. Da mesma forma, é um assunto instigante e que provoca a curiosidade nas pessoas.

O ensino de Astronomia baseia-se no contexto científico formal da educação, focando na investigação do universo baseado em dados científicos. Isso significa compreender para além da observação intuitiva, que, naturalmente, faz parte do ser humano, mas respeitando técnicas e métodos científicos na obtenção e interpretação de dados com a orientação do educador. 
O trabalho científico é construído a partir de dúvidas, perguntas, observações da natureza, elaboração de teorias e das conclusões que se podem tirar a partir da comparação dos resultados da teoria com as experimentações e observações. É um caminho árduo, que é trilhado por aqueles cujo dom principal talvez seja o de questionar... Opiniões muitas vezes estão baseadas em certezas, enquanto é o questionamento das certezas a fonte de inspiração para o desenvolvimento da ciência (ARANY-PRADO, 2017, p. 11).

Com isso, o educador deve orientar e mediar ações que se aproveitem dessa intuição, provocar o aprendiz com fatos e evidências cientificamente consolidados, possibilitar o reconhecimento da Ciência pelo aluno, como uma construção humana, racional e totalmente questionável, e considerar a Astronomia um meio para estabelecer conceitos e instigar a construção do pensamento científicos desses sujeitos.

Neste sentido, com o intuito de contribuir e investigar o ensino-aprendizagem de física para os sujeitos surdos, este trabalho assume a seguinte problemática: Quais as potencialidades do tema Astronomia em Libras aliadas às Tecnologias Digitais da Informação e Comunicação (TDICs) no processo de ensino-aprendizagem de Física para surdos? O objetivo principal é investigar quais a potencialidades do tema Astronomia em Libras aliada às TDIC no processo de ensino-aprendizagem de Física para surdos.

Para isso, realizamos um questionário on-line que sucedeu da realização de um minicurso. Elaboramos e ofertamos um minicurso em Libras, aliada ao uso de TDICs, o qual oferecemos durante a 7ạ Semana Acadêmica da Licenciatura em Ciências Exatas (Salce) e 1a Semana Acadêmica Integrada da Unipampa, campus Caçapava do Sul/RS, em novembro de 2016. Contamos com a participação de 15 pessoas, entre elas 2 surdos, integrantes da comunidade surda, licenciandos do curso de Ciências Exatas e professores, constituindo um grupo diversificado.

\section{CULTURA SURDA E ALGUNS DISPOSTOS LEGAIS NA PERSPECTIVA DA EDUCAÇÃO}

O movimento mundial de inclusão surgiu no final da década de 80 , tendo como base o princípio à igualdade nas oportunidades sociais e educacionais, e a relevância das variadas propostas na construção da aprendizagem (SILUK, 2012). Na Constituição Federal de 1988 é assegurado que o ensino deve ser ministrado com base nos princípios de igualdade e de condições para o acesso e permanência na escola (BRASIL, 1988).

Foi em 1994, porém, que se instituiu outro importante marco legal: a criação da Declaração de Salamanca, que trata dos "Princípios, Políticas e Práticas na Área das Necessidades Educativas Especiais", reforçando o compromisso com a educação para todos, que atenda com integridade às necessidades socioeducacionais, extrapolando as diferenças e visando à necessidade e à importância de transformações políticas, sociais, estruturais, tecnológicas, e, principalmente, no que respeita às inovações da prática pedagógica no sistema de ensino regular (BRASIL, 1994).

Referente aos direitos da pessoa surda ou deficiente auditiva, o ano de 2002 foi marcado pela oficialização da Libras, Lei 10.436/2002 (BRASIL, 2002). Essa lei é regulamentada pelo Decreto 5.626/2005 (BRASIL, 2005), que, em seu artigo 2ㅇ, especifica que 
a pessoa surda é aquela que compreende e interage com o mundo por meio de experiências visuais, manifestando sua cultura principalmente pelo uso da Libras (BRASIL, 2005).

Outro importante direito conquistado ocorreu com a regulamentação da Lei 12.319/10, em 2010. Essa lei assegura a presença de tradutores e intérpretes de Libras principalmente nas escolas (BRASIL, 2010).

Considerando a realidade brasileira na qual as escolas públicas e particulares têm surdos matriculados em diferentes níveis de escolarização, seria impossível atender às exigências legais que determinam o acesso e a permanência do aluno na escola observando-se suas especificidades sem a presença de intérpretes de língua de sinais. Assim, faz-se necessário investir na especialização do intérprete de língua de sinais da área da educação (QUADROS, 2004, p. 59).

Assim, torna-se indispensável para o processo de ensino-aprendizagem e para a formação integral dos estudantes surdos, a atuação contínua e permanente deste profissional. O intérprete de Libras é um instrumento para acessibilidade linguística e cultural do surdo. Sua atuação é um incentivador da permanência destes alunos no meio escolar. o intérprete deve apresentar fluência nas duas línguas envolvidas, que é o Português e a Libras, bem como possuir formação na área de educação (QUADROS, 2004).

No contexto educacional, muitas vezes a função desse profissional é confundida na comunidade escolar, o que ainda demanda reflexões, pois envolve um fazer que vai além da interpretação e da mediação da comunicação. Na educação dos surdos, ser intérprete perpassa os campos pedagógicos e de interlocutor.

Oliveira e Benite (2015) evidenciam, em suas pesquisas na área de educação em ciências, que, além das barreiras comunicativas nos ambientes bilíngues, o trabalho do intérprete se apresenta indefinido e há uma complicação nos papéis entre o professor e o intérprete. Com isso, propõem alternativas que podem contribuir nessas relações:

Nossos resultados permitem considerar, ainda, que o ensino de ciências só será possível por meio da atuação conjunta entre professor e Intérprete de Libras, no planejamento das atividades a serem desenvolvidas em sala de aula, e não somente no desenvolvimento de métodos e técnicas (p. 470).

Podemos inferir que o intérprete necessita transitar no campo pedagógico. Sem essa transição o trabalho desse profissional pode tornar-se delimitado ou sem sentido educacional. $O$ intérprete de Libras é um dos importantes vetores no processo de inclusão e acessibilidades linguísticas e culturais. Assim, é preciso que se repensem as estruturas e a postura desse profissional mediante o contexto educacional. Esse repensar é importante para que o ensino-aprendizagem seja contemplado com caráter eficiente na educação dos sujeitos surdos e deficientes auditivos.

Ainda em legislação, quanto à definição de indivíduo surdo ou deficiente auditivo há uma distinção conceitual no contexto clínico. Conforme o Decreto № 5.626/2005, é considerado deficiente auditivo o sujeito que tem perda bilateral, parcial ou total de 41 decibéis $(\mathrm{dB}$ ) ou mais, aferida por audiograma nas frequências de $500 \mathrm{~Hz}, 1.000 \mathrm{~Hz}$, $2.000 \mathrm{~Hz}$ e $3.000 \mathrm{~Hz}$ (BRASIL, 2005). 
No contexto cultural, Perlin (2004) e Strobel (2016) abordam a surdez como uma questão de identidade naturalmente emergente ao indivíduo surdo. A surdez é como uma característica intrínseca e distinta dos indivíduos ouvintes, tanto na forma como percebem o mundo quanto na sua língua e interação com o meio:

dentro do povo surdo, os sujeitos surdos não diferenciam um ao outro de acordo com o grau de surdez, mas o importante para eles é o pertencimento ao grupo usando a língua de sinais e cultura surda (STROBEL, 2016, p. 29).

O conceito de cultura ainda é diversificado e está em processo de construção. Strobel (2016) apresenta um suposto ou plausível significado ao termo cultura: uma herança que o grupo social transmite aos seus membros pela aprendizagem e convivência, em que as gerações e sujeitos contribuem na sua modificação, tanto do que é externo quanto o que temos dentro de nós. Os elementos mais importantes de uma cultura são as habilidades dos sujeitos com a construção de sua identidade e o uso da linguagem nas produções coletivas do ser humano, não do homem isolado.

É neste caminho que entender a educação dos surdos ultrapassa concepções clínicas, audiológicas e de reabilitação. Requer um conhecimento que aponte para as questões da diferença, da cultura e da identidade cultural do surdo. Isto é, do seu pertencimento a uma cultura própria e da sua interação em uma comunidade. É preciso perceber e refletir sobre a surdez como uma diferença que se constrói nas vivências cotidianas das comunidades surdas, sendo mais evidente as características sociolinguísticas (STROBEL, 2016).

Para Strobel (2016), os sujeitos surdos experienciam o mundo por meio de seus olhos e de tudo que circunda esse sentido, incluindo uma percepção visual e corporal do ambiente:

Os sujeitos surdos, com ausência de audição e do som, percebem o mundo através de seus olhos e de tudo o que ocorre ao redor deles: desde os lábios de um cachorro - que são demonstrados por meio dos movimentos de sua boca e da expressão corpórea-facial bruta - até de uma bomba estourando, que é óbvia aos olhos de um sujeito surdo pelas alterações ocorridas no ambiente, como os objetos que caem abruptamente e a fumaça que surge (STROBEL, 2016, p. 45).

Neste sentido, entende-se que as relações e o processo cognitivo do surdo acontecem mediante as experiências visuais com espaço. Essas relações são mediadas pelo seu instrumento natural de comunicação, que é a língua de sinais. Lembrando que essa se caracteriza como sua primeira língua, o que constitui o "símbolo da surdez" (BRITO, 1993). Além de ser uma língua visual-espacial articulada por meio das mãos, das expressões faciais e do corpo (QUADROS; PELIN, 2007), é uma língua plena, e não um código artificial de comunicação; deve ser reconhecida como um direito dos surdos (SKLIAR, 1997).

A sociedade, composta por uma maioria de ouvintes, desconhece a cultura surda e que há uma cultura própria dos surdos. Por isso, geralmente, os percebem como pessoas que não interagem e não possuem vida social, pelo fato de não ouvirem ou falarem oralmente (STROBEL, 2016). É justamente sobre essa falta de conhecimento e informação a respeito das características dos sujeitos surdos, que a educação de surdos vem 
modificando a integração dessas pessoas e a sua percepção pela sociedade, passando a construir conexões sociais e desconstruir preconceitos, principalmente no ambiente educacional. Essas mudanças envolvem tanto a escola inclusiva, quanto as especiais bilíngues para surdos.

Stumpf (2008) argumenta a respeito do papel da escola inclusiva e o quanto esta tem falhado na inclusão dos alunos surdos. Geralmente as dinâmicas educacionais focam a língua oral e a escrita da mesma forma. $O$ aluno surdo inserido no espaço educacional com ouvintes e sem os suportes adequados, todavia, passa a se comportar como um deles, perdendo sua identidade e cultura próprias. "O cultivo da linguagem e da identidade são, então, os elementos fundamentais de uma cultura" (STROBEL, 2016, p. 23). Stumpf (2008) argumenta a respeito do papel da escola inclusiva e o quanto esta tem falhado na inclusão dos alunos surdos, pois não se trabalha os conteúdos (grade curricular) em proximidade à cultura surda. A autora nomeou essa aproximação de conteúdos com a cultura surda como uma Pedagogia Surda.

A intenção, aqui no Brasil, é a construção de uma Pedagogia Surda com uma perspectiva que visa o direito e à oportunidade eminente à criança surda de "viver sua cultura desde sempre e que a pedagogia surda precisa estar presente o quanto antes possível na realidade cotidiana da criança surda" (STUMPF, 2008, p. 18), como uma estratégia na formação intelectual e social destes sujeitos.

Quanto à educação bilíngue em escolas especiais para surdos, compreendemos que o bilinguismo prioriza e favorece a aquisição da língua natural do surdo. Assim, "o bilinguismo, sendo bem utilizado, somado a todas as estimulações que o surdo pode ter, oferece iguais condições de aprendizagem e desenvolvimento destes alunos em comparação aos alunos ouvintes" (MENEZES; CARDOSO, 2011, p. 9).

A construção de uma nova história cultural caracteriza-se como um desafio a ser enfrentado pelo povo surdo, com o reconhecimento, respeito e valorização das diferenças e da língua, além da emancipação dos sujeitos surdos da opressão ouvinista e a liberdade de evolução da identidade cultural (STROBEL, 2016).

\section{ASTRONOMIA E AS TECNOLOGIAS NO ENSINO DE FÍSICA}

A investigação do universo, de sua composição, formação e influências, que, mais tarde, denominou-se de Astronomia, foi atividade humana que certamente deu início ao mundo das ciências.

Ainda na pré-história as pessoas observavam e notavam a existência de mecanismos e ciclos específicos que se manifestavam e interferiam em suas atividades terrenas, em geral marcadas pela posição das estrelas. Foi neste sentido que os antigos puderam construir seu primeiro contato com a noção de ciência (NOGUEIRA, 2009).

Horvath (2008) enfatiza que não sabemos definitivamente como os estudos astronômicos começaram, mas a maior evidência é provavelmente pela curiosidade humana pelos céus. É na curiosidade e na imersão no desconhecido que se encontra a capacidade de movimentar os saberes. Isto é: "o verdadeiro conhecimento é o que resulta 
divertido e satisfaz a curiosidade das pessoas, enquanto pouco tem de divertido "ficar por fora" somente ouvindo uma série de termos e definições sem realmente entrar nos temas" (HORVATH, 2008, p. 12).

Segundo Kepler e Saraiva (2014), o estudo da Astronomia fascina as pessoas desde antigamente, pois a curiosidade para saber o que há além do que podemos enxergar sempre foi algo inevitável à mente humana. $E$ neste sentido que se pode pensar na justificativa para o estudo da Astronomia. O universo é uma fonte de exploração e satisfação de muitas curiosidades que satisfazem o ser humano intelectual e tecnologicamente:

Nosso objetivo é utilizar o Universo como laboratório, deduzindo de sua observação as leis físicas que poderão ser utilizadas em coisas muito práticas, desde prever as marés e estudar a queda de asteróides sobre nossas cabeças, os efeitos do Sol sobre as redes de energia e comunicação, até como funcionam os reatores nucleares, analisar o aquecimento da atmosfera por efeito estufa causado pela poluição, necessários para a sobrevivência e desenvolvimento da raça humana (KEPLER; SARAIVA, 2014, p. 21).

Nesta perspectiva, pensando na Astronomia como a base da Ciência e, de acordo com os Parâmetros Curriculares Nacional (PCNs), "A Ciência Moderna se inicia com os trabalhos de Copérnico, Kepler e Galileu (séculos XVI e XVII) na Astronomia" (BRASIL, 1998, p. 24). Atualmente percebe-se sua influência em muitas áreas do conhecimento científico (NOGUEIRA, 2009) e na disseminação de diversas tecnologias.

Ainda conforme os PCNs: "Na história das Ciências são notáveis as novas teorias, especialmente a partir do século XVI, quando começa a surgir a Ciência Moderna, cujos resultados ampliam as relações entre Ciência e Tecnologia" (BRASIL, 1998, p. 24). Referente ao sentido do aprendizado na área de Ciências, o estudo de Astronomia é de grande importância na formação do pensamento científico, devendo ser iniciado no Ensino Fundamental e continuado no Ensino Médio (BRASIL, 2000). Geralmente, no entanto, o ensino de Astronomia é presenciado apenas na disciplina de Geografia, durante o 6으 ano do Ensino Fundamental (NOGUEIRA, 2009).

Nas pesquisas realizadas por Langhi e Nardi $(2009,2014)$, os autores perceberam investimentos e um sensível aumento em pesquisas que abordam a Educação em Astronomia nas últimas décadas, tornando a temática uma preocupação crescente em diversas pesquisas brasileiras, mais acentuada a partir de 2000. Os autores destacam que esse aumento ocorreu, talvez, em virtude da influência da produção dos documentos do Ministério da Educação, como o PCN (LANGHI; NARDI, 2014).

Ao tratar das pesquisas referentes ao ensino de Astronomia, Langhi e Nardi (2009) afirmam que nas últimas décadas foram produzidas mais teses, dissertações, desde 1973 (quando surgiu o primeiro trabalho neste sentido), e trabalhos de iniciação científica. Consequentemente, um considerável volume de trabalhos vem sendo publicado em periódicos e apresentado em eventos nacionais e internacionais da área (2009), como no Simpósio Nacional de Ensino de Física (SNEF), no Encontro Nacional de Pesquisa em Ensino de Ciências (Enpec) e no Encontro de Pesquisa em Ensino de Física (Epef).

Com intenção de estabelecer um panorama geral da educação em Astronomia, Langhi e Nardi (2009) destacam que, na educação básica, a promoção do estudo de conteúdos de Astronomia ocorre de modo reduzido e, muitas vezes, até nulo. Estes con- 
teúdos são sugeridos por órgãos e documentos oficiais. Quando ocorrem, os conteúdos de Astronomia são administrados por opção de professores comprometidos com sua formação continuada individual, tornando presentes tópicos de Astronomia nas aulas de Ciências ou de Física (2009).

Lembramos que o foco desta pesquisa é a relação entre o ensino-aprendizagem de Astronomia na educação de surdos. Assim, realizamos uma consulta nos sites oficiais no sistema de busca dos Anais desses três maiores eventos da área de ensino de Física. Nas últimas edições dessa década, no período de 2010 a 2018, encontramos apenas três artigos que abordam o assunto: um no XIX SNEF (2011) de Menezes e Cardoso (2011), um no XX SNEF (2013) dos autores Santos et al. (2013) e outro no XXII SNEF (2017), esse último de autoria dos pesquisadores Vivian e Leonel (2017). ${ }^{3}$ Evidenciamos, com esta busca, uma recorrente necessidade de investimentos em pesquisas nesse sentido

Para a educação de surdos o potencial que o estudo de Astronomia pode proporcionar merece atenção, pois com as barreiras comunicativas enfrentadas na educação de surdos o ensino-aprendizagem científico pode ser prejudicado para o sujeito surdo. Nunes (2017, p. 36) ressalta que: "a dificuldade de ensinar Astronomia para os alunos surdos não está apenas nos conceitos de Astronomia que são os mesmos encontrados para os alunos ouvintes". Muitas vezes, a ausência de sinais específicos na língua de sinais fragmenta o processo de ensino-aprendizagem dos estudantes surdos; logo, a construção de sinais para terminologias científicas é pertinente e necessária para a educação científica desses sujeitos (VARGAS; GOBARA 2013, 2015a, 2015b; SANTOS et al., 2013; PASSERO; BOTAN; CARDOSO, 2011). É nesse caminho que pesquisas abrangendo a criação de sinais para a área da Física tem se intensificado.

Devemos considerar como outra estratégia fundamental, para que o processo de ensino-aprendizagem desses sujeitos aconteça, o uso das tecnologias. Essa estratégia vai além de uma ferramenta de manipulação. Consiste em uma viabilidade prática. Segundo o PCN, "A associação entre Ciência e Tecnologia se amplia, tornando-se mais presente no cotidiano e modificando, cada vez mais, o mundo e o próprio ser humano" (BRASIL 1998, p. 23).

Stumpf (2008) argumenta a respeito das opções de mídia e tecnologia para a Pedagogia Surda com o viés de:

enfatizar o uso da tecnologia como ferramenta pedagógica de intervenção no processo de comunicação escrita ou visual e interação social dos sujeitos envolvidos. As tecnologias: vídeos, DVD, página de internet, blog, comunidade virtual, e-mail, chat, webcam, escrita de Língua de Sinais, o celular com suas mensagens, retroprojetores, a TV oportunizam e motivam essas participações. Podemos inferir que as tecnologias referidas foram utilizadas como ferramentas pedagógicas surdas, nas escolas pioneiras... Isto reflete na proposta de uso de tecnologias avançadas na Pedagogia Surda (STUMPF, 2008, p. 16).

O artigo apresentado por Vivian e Leonel (2017) é referente aos estudos de Astronomia realizados com um grupo de estudantes surdas em 2016, envolvendo a construção de sinais para a área da Astronomia e que igualmente utilizamos na pesquisa que propomos aqui. 
Segundo Almeida e Silva (2011), o uso de TDIC na educação contribui para a mudança das práticas educativas envolvendo a elaboração de novas perspectivas. Essa mudança perpassa tanto a sala de aula quanto a ação pedagógica e as relações entre ensino-aprendizagem. Inclui-se as TDIC como materiais didáticos na organização e representação das informações por meio de múltiplas linguagens.

A expansão das TDIC, principalmente por meio dos computadores e da internet, reflete uma configuração social e uma cultura baseada num modelo digital de pensar, criar, produzir, comunicar, aprender e viver (ALMEIDA; SILVA, 2011), como exposto nas ideias de Lévy (1996) sobre a importância da realidade virtual como meio de perpassar conceitos abstratos, independentemente de meios físicos e imediatos.

Não é de hoje que a literatura aponta o potencial das TDIC para o ensino de ciências, incluindo-se a Física, em razão das possibilidades de comunicação, de organização e disponibilização de objetos de aprendizagem, otimização do tempo, atualização curricular, interação, colaboração e participação ativa dos estudantes no processo de ensino-aprendizagem, exploração das diferentes linguagens, simulações e observação de fenômenos diversos, registros nas formas mais variadas possíveis, além das contribuições para a formação científica e técnica, garantindo maior autonomia, capacidade de comunicação, domínio e responsabilidade ante as situações concretas (ARTUSO, 2006; MAIA, MENDONÇA; STRUCHINER, 2007; ESPÍNDOLA, 2010; LEONEL, 2013, 2015; SANTOS; LEONEL; SCHWEDER, 2013).

Assim como Espíndola (2010), esta investigação assume a compreensão de que a integração das TDIC não se reduz à seleção e uso entre os diversos recursos tecnológicos disponíveis atualmente, "mas se realiza a partir de um processo de articulação das potencialidades destas ferramentas aos conhecimentos e saberes dos professores no desenvolvimento de possibilidades educativas para seus contextos de ensino" (p.18). Também se fortalece com Moran, Masetto e Behrens (2001), ao enfatizar que: "Ensinar com as novas mídias será uma revolução se mudarmos simultaneamente os paradigmas convencionais do ensino, que mantêm distantes professores e alunos ..." (p. 63).

É nesse sentido que aplicativos e artefatos tecnológicos têm sido utilizados. Softwares para o ensino-aprendizagem de Astronomia são importantes ferramentas para a exploração de diversos fenômenos, difíceis ou impossíveis de serem reproduzidos materialmente pelos estudantes, pois muitos fenômenos astronômicos não podem ser observados em razão das grandes escalas espaciais e temporais envolvidas.

Consideramos, então, que os programas Stellarium e Celestia podem contribuir para o ensino-aprendizagem de Astronomia, integrando, a esses, o papel provocador e a postura problematizadora que o professor deve atribuir a estas ferramentas. Além disso, os programas selecionados para esta pesquisa apresentam uma proximidade convergente com a percepção que o surdo estabelece com o meio, ou seja, mediante o campo visual. 


\section{METODOLOGIA E CONTEXTO DA PESQUISA}

Esta pesquisa possui uma abordagem qualitativa (LÜDKE; ANDRÉ, 1986). Foi empregadas a análise de conteúdo para tratamento dos dados obtidos, que é uma técnica de investigação que tem a finalidade de descrição objetiva, sistemática e recorrente do conteúdo manifesto da comunicação (BARDIN, 2011).

Foi desenvolvido um minicurso com a intenção de investigar quais as potencialidades do tema Astronomia em Libras aliada às TDIC no processo de ensino-aprendizagem de Física durante a 7ạ Salce e a 1a Semana Acadêmica Integrada da Unipampa, campus Caçapava do Sul/RS, em novembro de 2016. O minicurso foi planejado por um dos autores deste trabalho, que atua como professora intérprete de Libras e possui formação em Ciências Exatas com habilitação para o ensino de Física.

Contamos no minicurso com a presença e a participação de um grupo de 15 pessoas. Entre elas 2 surdos, integrantes e representantes da comunidade surda (intérpretes de Libras atuantes e em formação), licenciandos do curso de Ciências Exatas e professores da rede pública de ensino das esferas municipal, estadual e federal, Formando, assim, um público heterogêneo.

Considerando a diversidade do público participante do minicurso, tivemos como principais tópicos de discussões: apresentar noções básicas de Astronomia; informações sobre cultura surda e acessibilidade; e aspectos para a integração social e educacional.

Em geral, discutimos nesse minicurso sobre inclusão, bilinguismo e o processo de ensino-aprendizagem de Física e de Astronomia para a educação de surdos. Para essas discussões, seguimos os pressupostos teóricos até aqui apresentados. A articulação do minicurso ocorreu mediada em Libras e com o uso de TDICs, considerando diálogos em uma perspectiva gestual, visual e oral.

Começamos o minicurso apresentando e ensinando alguns sinais básicos para comunicação em Libras, como o alfabeto datilológico, identificação pessoal e cumprimentos. A pretensão era que os ouvintes pudessem ter um contato com a língua e, consequentemente, possibilitar uma comunicação entre os mesmos com os surdos. Com isso, abordamos aspectos culturais, linguísticos e legais na educação de surdos.

Em sequência, houve uma explicação sobre alguns conceitos e objetos astronômicos. Para isso, utilizamos slides com fotos, vídeos e as representações dos astros em língua de sinais, além do uso de sinais que foram criados durante os estudos realizados com um grupo de alunas surdas em pesquisas anteriores, realizadas por Vivian e Leonel (2017).

Para finalizar o minicurso, apresentamos e discutimos a importância da criação de sinais e do uso de TDIC no ensino-aprendizagem de Física. Escolhemos dois softwares de Astronomia para manipulação, sendo eles Stellarium e Celestia. Realizamos, então, explorações com os softwares para que os participantes interagissem com os programas e experimentassem suas potencialidades.

O minicurso serviu como embasamento teórico e prático sobre estratégias didático-metodológicas para que os participantes pudessem manifestar, posteriormente, em um questionário, as suas percepções, motivações e possíveis sugestões e reflexões para o ensino-aprendizagem de Astronomia na educação de surdos. 
Bardin (1977) define que a análise de conteúdo consiste em instrumentos metodológicos que abrangem discursos relacionados com a análise de comunicações. Neste viés, estruturamos um questionário on-line ${ }^{4}$ como instrumento para análise das concepções dos participantes. Esse foi respondido após a realização do minicurso.

Enviamos um e-mail aos participantes contendo a apresentação dos slides e um convite para que respondessem ao questionário on-line, que se constituiu como principal meio de percepção da aceitação dos participantes sobre as potencialidades da temática.

Como poucos se manifestaram, reenviamos uma segunda solicitação, também por e-mail, para que mais pessoas respondessem o mesmo. Ao final, alcançamos um total de seis participações, as quais identificamos como Participante $A, B \ldots$ (PA, PB...): PA, PB, PC, PD, PE e PF.

O questionário foi composto por 13 questões, sendo 10 dissertativas e 3 objetivas, conforme mostramos no Quadro 1.

Quadro 1 - Questionário de avaliação

\begin{tabular}{|l|}
\multicolumn{1}{|c|}{ Avaliação sobre Tópicos de Astronomia em Libras } \\
\hline 1) Você considera que o minicurso contribuiu com o seu entendimento acerca da cultura \\
surda? Descreva de que forma. \\
\hline 2) Entre os aspectos abordados acerca da Língua Brasileira de Sinais (Libras) e da Cultura \\
Surda, quais você considera mais significativos para sua formação acadêmica ou prática do- \\
cente? \\
\hline 3) Você considera que o minicurso contribuiu com o seu entendimento no que se refere ao \\
Ensino de Física para pessoas surdas? Descreva de que forma. \\
\hline $\begin{array}{l}\text { 4) Quais tópicos de Astronomia articulados com Libras tiveram maior relevância na sua for- } \\
\text { mação ou ação docente? Por quê? }\end{array}$ \\
\hline 5) Referente à manipulação dos softwares Stellarium e Celestia, destaque os potenciais que \\
estes oferecem enquanto recursos para o Ensino de Astronomia? \\
\hline 6) Sobre o uso das Tecnologias Digitais da Informação e Comunicação (TDIC), em sua opinião \\
quais são as principais potencialidades e possibilidades para o Ensino de Física e na Educa- \\
ção de Surdos? \\
\hline 7) Pensando na contribuição do minicurso para a sua formação, que nota você atribui, entre \\
1 e 5, sendo 1 a nota mínima e 5 a nota máxima, para os seguintes pontos: Organização do \\
minicurso, Tópicos de Astronomia abordados, Tópicos relacionados à cultura surda, Uso dos \\
aplicativos Stellarium e Celestia, Tópicos relacionados ao ensino de Física para pessoas surdas. \\
\hline 8) No que diz respeito às questões abordadas no minicurso, como você avalia a relevância \\
das mesmas: Ensino de Astronomia, Cultura Surda, Uso de aplicativos no ensino de Física \\
para surdos, Uso das TDIC para o ensino de Física. (Irrelevante, Relevante, Muito relevante) \\
\hline 9) Na sua opinião, qual foi a maior contribuição do minicurso? \\
\hline 10) Você considera que o minicurso atingiu suas expectativas? \\
\hline 11) Você considera que o curso deixou a desejar em algum aspecto? Qual(is)? \\
\hline 12) Você teria interesse em fazer outro minicurso sobre este tema? \\
\hline 13) Quais tópicos gostaria que fossem abordados caso fosse oferecido outro minicurso? \\
\hline
\end{tabular}

Fonte: Dados da pesquisa.

${ }^{4}$ Elaborado por meio da ferramenta "formulários" Google, disponível na rede. 
Enfatizamos que, de acordo com Bardin (1977), na análise de conteúdo qualitativa para o tratamento do material precisamos transformar os dados brutos do texto por meio de recortes (escolha das unidades) ou fragmentos, classificação e agregação (escolha das categorias). Neste caso, o texto refere-se às respostas dos participantes ao questionário e os fragmentos conferem as falas de maior relevância com nosso objetivo.

Neste sentido, analisamos e sistematizamos as respostas às questões de avaliação em quatro categorias que definimos a priori, por apresentarem maior recorrência nas perguntas e maior proximidade com o problema e objetivo da investigação.

Assim, denominamos as quatro categorias: 1) Cultura Surda, Libras e Astronomia no Ensino de Física; 2) Tópicos de Astronomia para Surdos; 3) TDIC no Ensino de Física para Surdos; 4) Ensino de Física para Surdos. Nessas categorias discutimos a percepção dos participantes e as potencialidades da articulação entre Astronomia, Libras e TDIC para a educação de surdos.

\section{RESULTADOS E ANÁLISES}

Com o questionário de avaliação (Quadro 1) percebemos e reconhecemos as reflexões e implicações da comunidade surda e dos ouvintes participantes sobre a articulação de Astronomia, Libras e de TDIC no ensino-aprendizagem de Física para surdos, bem como as possibilidades e estratégias didático-metodológicas relevantes para a educação dos surdos. Abordamos sucessivamente em quatro categorias os apontamentos e contribuições levantados pelos participantes PA, PB, PC, PD, PE e PF.

Na categoria 1) Cultura Surda, Libras e Astronomia no Ensino de Física, notamos que a apresentação sobre aspectos culturais e linguísticos, característicos do povo surdo, instigou o interesse dos participantes.

Os participantes PA, PB, PC e PE relataram acreditar que o conhecimento dessas especificidades contribui para o ensino-aprendizagem de Física e também agrega um diferencial tanto na formação inicial dos licenciandos quanto para a prática docente dos professores presentes. Dessa forma, instigam a elaboração de estratégias didático-metodológicas que possam promover a inclusão e permanência dos sujeitos surdos na escola.

Nos discursos de PA e PB também evidenciamos o desconhecimento da cultura e da língua própria dos surdos pelos participantes, mas notamos que ambos reconhecem a necessidade de compreender essas especificidades como um fator a ser potencializado e presente na ação docente. Vejamos no excerto a seguir:

PA: Eu desconhecia muitas coisas, agora já estou mais segura, vou saber como agir na sala de aula. Considero mais importante que o professor tenha conhecimento sobre a língua, pois na sala de aula pode ter alunos que necessitem de uma atenção especial; deve também saber aplicar os conhecimentos de uma forma mais fácil de ser compreendida.

PB: Com certeza contribuiu muito, exemplo a cultura e alguns costumes que eram desconhecidos por mim, a maneira de se comunicar usando de outros recursos além dos sinais. A comunicação por sinais é algo normalmente deixado de lado e 
tão pouco visto e incentivado durante a Graduação que ficou visível que todos devem investir pelo menos um pouco (Respostas dos participantes ao questionário, novembro de 2016).

Para os participantes PC e PE, o contato com os surdos é fundamental para a comunicação e a proposta do minicurso possibilitou a compreensão de que existe e de como é a cultura surda. Do mesmo modo, reconheceram que há potenciais possibilidades para o ensino-aprendizagem de Astronomia com a utilização de recursos tecnológicos digitais como estratégia que viabiliza e favorece o ensino-aprendizagem de deficientes auditivos e surdos, como mostramos no próximo excerto:

PC: A participação neste minicurso me proporcionou um melhor entendimento acerca da cultura surda, pois neste tive contato com a Língua Brasileira de Sinais aprendendo a me comunicar com este público, como também pude aprender como utilizar recursos como softwares para ministrar aulas de astronomia possibilitando a assimilação do conteúdo para deficientes auditivos e surdos. A comunicação através da Libras e maneiras de proporcionar o conhecimento, tanto para surdos quanto para qualquer outro tipo de público com deficiências, é de extrema importância para formação acadêmica e prática docente, uma vez que o professor busca proporcionar a inclusão entre os demais.

PE: Contribui para o meu conhecimento e curiosidade acerca da Libras e Astronomia. Acredito que uma complementa a outra e quanto mais contato com os surdos fluentes em Libras melhor o aprendizado (Respostas dos participantes ao questionário, novembro de 2016).

De modo geral, os participantes perceberam a importância do conhecimento da cultura e língua materna dos surdos como elementos necessários na efetivação do processo de integração e inclusão desses sujeitos. Segundo Quadros (2008) e Strobel (2016), a inclusão do sujeito surdo deve estar pautada no respeito à diversidade e aceitação da diferença, por meio de estratégias que não imponham uma cultura oralista, mas que a aproxime por intermédio de representações visuais.

Tantos anos de preconceito e exclusão social somente serão apagados com essa aproximação de ambas as culturas e de muito esforço conjunto e trabalho individual da comunidade surda brasileira, composta por "surdos e ouvintes comprometidos com o sonho de um futuro melhor para todos", salienta Ramos na apresentação da obra Estudo de Surdos III (QUADROS, 2008, p. 2).

Sobre a categoria 2) Tópicos de Astronomia para Surdos, os participantes PA, PB e PC concordaram que o tema é relevante para o ensino de Física para surdos. Destacaram que a criação de sinais para representar os significados e identificar os corpos celestes, é uma estratégia que contribui na compreensão e explicação dos conceitos para estes sujeitos.

A criação de sinais é uma ação necessária para o ensino-aprendizagem de Física na educação de surdos (VARGAS; GOBARA 2013, 2015a, 2015b; SANTOS et al., 2013; PASSERO; BOTAN; CARDOSO, 2011).

PA: Os símbolos foram criados para que o aluno soubesse do que o professor estava se referindo. (...) assim fica mais fácil a compreensão. 
PB: No momento que foi explicado as distâncias e todos os sinais articulados achei que fosse impossível, mas foi impressionante.

PC: Possuíram grande relevância para minha formação, uma vez que, como futuramente atuarei como docente na área da física, será necessário que domine estes conteúdos (Respostas dos participantes ao questionário, novembro de 2016).

Com a fala de PB vimos que há uma impressão equivocada, mas recorrente sobre o ensino-aprendizagem de Física para alunos surdos, com uma visão utópica sobre as possibilidades para sua efetivação. Conseguimos apresentar e provocar, entretanto, os participantes sobre as possibilidades e potenciais estratégias didático-metodológicas na educação científica para surdos.

Como apontou Strobel (2016), os ouvintes têm dificuldades em entender como os surdos compreendem o mundo. Por isso, como afirmou PB, sua primeira reação ao ser confrontado com as estratégias visuais foi a surpresa de que é possível aproximar-se da cultura do sujeito surdo considerando sua língua e suas vivências de modo visual.

Percebemos que a articulação de Astronomia em Libras proporcionou diversas possibilidades de explorar conceitos físicos, e se constituiu um diferencial para a formação dos participantes; que conheceram diferentes estratégias para contribuir com a educação dos surdos. Adaptar e atribuir sinais, mesmo que provisórios, em Astronomia e Física, garantem potencial para compreensão e divulgação dos conceitos.

Com as barreiras na comunicação e diálogo, que ocorrem pela distinção linguística e cultural, reconhecemos que o processo de adaptação conceitual implica considerar a língua natural do sujeito surdo e sua cultura. Na ausência de sinais específicos dos conceitos científicos dessa língua, a criação de sinais contempla uma importante estratégia para promover o ensino-aprendizagem de Física.

Quanto ao estudo de Astronomia, reconhecendo sua relevância histórica epistemológica para a educação científica, os resultados obtidos no questionário reafirmam e elucidam os apontamentos referendados nos documentos proposto pelo MEC. Isso atribui à Astronomia, entre outros ramos das Ciências Naturais, um caráter gerador de "representações do mundo ao buscar compreensão sobre o Universo, o espaço, o tempo, a matéria, o ser humano, a vida, seus processos e transformações" (BRASIL, 1998, p. 23).

Quanto à categoria referente a 3) TDIC no Ensino de Física para surdos, os participantes PA, PB, PC, PD e PF relataram que o maior potencial das mesmas é a visualização dos fenômenos, principalmente no caso dos surdos que necessitam da linguagem visual; além de proporcionar maior interatividade e compreensão.

PA: O uso de softwares e aplicativos, pois acho que é mais fácil eles estarem visualizando.

PB: Facilitam e possibilitam uma melhor visualização e interatividade.

PC: Grande potencial para visualização dos fenômenos (...) e assimilação dos conteúdos. Contribui, ensinando a manusear ferramentas que possibilitam o ensino de física para pessoas surdas (Respostas dos participantes ao questionário, novembro de 2016). 
Para PD, "o uso de tecnologias é bom em qualquer tipo de ensino na atualidade" (resposta do participante ao questionário em novembro de 2016). Ou seja, além de ser uma emergência na atualidade, as potencialidades das tecnologias devem ser repensadas para envolver todo o âmbito educacional (ALMEIDA; SILVA, 2011). O participante PF complementou essa ideia, reconhecendo que as tecnologias são artefatos promissores para o envolvimento do surdo com os conceitos.

PF: Conhecimento das mídias e tecnologias de uso da Física que podem ser utilizadas para maior compreensão dos aspectos relativos ao ensino da disciplina, na qual os surdos podem ser beneficiados (...) Estes softwares permitem que se tenha a riqueza de detalhes visuais através do 3D, além de exibir informações e a exploração do universo, informações dos corpos celestes, observação de estrelas, constelações, planetas, aglomerados como se fossemos viajantes do espaço (...) a possibilidade de visualizar a informação prestadas com a riqueza dos detalhes, que às vezes, só com o uso da língua não é possível (Resposta do participante ao questionário, novembro de 2016).

Os softwares para o ensino-aprendizagem de Astronomia demonstraram a capacidade de interação dos sujeitos com os fenômenos e o potencial apontado por Lévy (1996) de romper barreiras de espaço e tempo, bem como vislumbraram o aspecto cultural, fundamental para a percepção do surdo pela linguagem baseada no campo visual.

Referente à categoria 4) Ensino de Física para Surdos, os participantes PB, PE e PF relataram desde a carência do domínio dos conceitos físicos até a importância de repensar as ações didáticas e metodológicas quando se pensa na educação inclusiva para surdos.

PB: O professor deve se preocupar em transformar o conteúdo em algo que aluno sempre possa entender. A aprendizagem sobre a língua, e de como adaptar esses tópicos para ensinar os alunos.

PE: Acho difícil a área da Física e isso me faz querer aprender mais.

PF: Todo e qualquer conteúdo de aprendizagem e conhecimento pode e deve ser assunto a ser trabalhado com os surdos, desde que estejam acessíveis (profissionais sensíveis, qualificados e dispostos a aprender sempre, uso da Língua materna para o ensino - Libras, Intérprete de Libras, utilização de recursos visuais, utilização de mídias e tecnologias adequadas) (Respostas dos participantes ao questionário, novembro de 2016).

É preciso investir na transformação da prática de professores e de intérpretes de Libras com a oferta de formação continuada, envolvendo esses profissionais com a língua e a cultura surda. Do mesmo modo, os intérpretes devem ter um contato maior com os conceitos específicos da área. Análogo, é preciso que haja a disponibilização de materiais didático-metodológicos e tecnológicos para contribuir na atuação desses educadores.

Em ambientes inclusivos, o professor da disciplina e o intérprete são atuantes; nesse sentido ambos os profissionais são educadores. Além disso, as adaptações de conteúdo e linguística são dependentes de um trabalho conjunto, que possibilite essas articulações e favoreça a comunicação científica com o estudante surdo. 
Com isto, o uso de estratégias diferenciadas deve ser parte do trabalho do professor e integrado com o intérprete. O professor da disciplina deve estar atento às especificidades dos alunos, procurando atendê-los com objetividade, respeitando e reconhecendo suas necessidades como parte fundamental do processo de ensino-aprendizagem.

Ainda na categoria 4), outro aspecto que evidenciamos foi a importância do domínio da Libras seja pela intérprete em um ambiente inclusivo ou com professores bilíngues, no caso de classes que priorizem o bilinguismo. Segundo o participante PE: "Ter o profissional que domine a Língua de Sinais para que seja o mediador da comunicação ou docente domine a sua disciplina e Libras" (resposta do participante ao questionário em novembro de 2016). O participante reforçou o conhecimento da língua materna do surdo como forma de potencializar o ensino-aprendizagem de Física para pessoas surdas. Concordando com os apontamentos de Menezes e Cardoso (2011) sobre a educação bilíngue no ensino de física e para a formação integral do surdo.

Este é um dos importantes aspectos para uma abordagem educacional bilíngue e intercultural, como apontam Quadros (2008), Strobel (2016) e Nunes (2017). Nesta perspectiva, PF referiu-se sobre a acessibilidade como forma de respeito aos sujeitos surdos e afirmou que:

PF: Considero que o minicurso, estando acessível em Libras, contribuiu para a compreensão da temática abordada, possibilitando aos surdos presentes e aos ouvintes fluentes em Libras o entendimento do assunto, a participação e a reflexão do tema. O minicurso, ao utilizar-se de elementos da cultura surda (prioridade na utilização de elementos visuais, uso da Libras para desenvolvimento da oficina, mediação através de Intérpretes de Libras e respeito aos surdos) teve enorme êxito em seu objetivo (Resposta do participante ao questionário, novembro de 2016).

Em outros relatos, os participantes alegaram que uma das contribuições do minicurso foi proporcionar a participação do público surdo. Segundo PE: "ter oportunizado este momento incluindo os surdos, pois geralmente só se pensa nas pessoas ouvintes" (resposta do participante ao questionário em novembro de 2016). As atividades ou eventos públicos são propostas, em sua maioria, pensando apenas no público ouvinte. Ao incluirmos pessoas surdas no minicurso, promovemos uma melhor aproximação entre a comunidade surda local e ouvintes.

Quanto à relevância dos elementos investigados na questão 8: Ensino de Astronomia, cultura surda, uso de aplicativos no ensino de Física para surdos e uso das TDIC para o ensino de Física, é possível conferir que a maioria dos participantes considerou que se tratam de elementos de muita relevância.

Percebemos um destaque com relação ao "uso das TDIC para o ensino de Física", o qual foi considerado muito relevante por $100 \%$ dos participantes. Os participantes também afirmaram que gostariam de ter outras oportunidades para aprofundamento tanto de Astronomia quanto sobre a cultura surda, para melhor qualificação profissional e prática docente. 
Figura 1 - Gráfico de relevância dos itens da questão 8 do Quadro 1

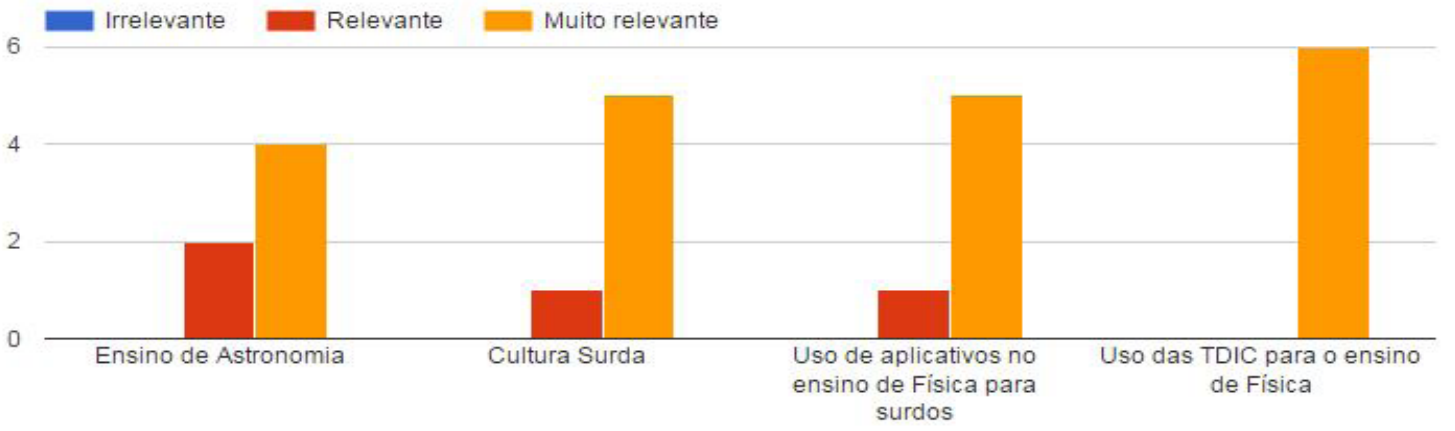

Fonte: Os autores.

Revelamos que esta articulação é uma temática que requer maiores investimentos, pois a proposta do minicurso, promoveu significativas reflexões de surdos e de ouvintes sobre o potencial na articulação entre Astronomia, Libras e TDIC no processo de ensino-aprendizagem de Física na cultura surda.

\section{CONSIDERAÇÕES FINAIS}

Mesmo com a associação de poucos participantes no questionário, consideramos que, na perspectiva qualitativa, as falas desses foram significativas para que percebêssemos o potencial da Astronomia em Libras articulada às TDIC para a cultura surda.

Os participantes consideram o tema Astronomia de grande relevância para o ensino-aprendizagem de Física para pessoas surdas, em razão de a temática possibilitar uma abordagem que pode ser discutida tanto no contexto histórico quanto em uma perspectiva atual. Os participantes concordam e reconhecem que a Astronomia instiga a curiosidade, o interesse pela Ciência, formação científica e uma atitude questionadora dos sujeitos.

Defendem, igualmente, que o uso das TDICs, além de viabilizar a educação para a cultura surda, facilita a apresentação dos fenômenos e a percepção visual dos conceitos envolvidos e colabora na prática docente, contribuindo com o processo de ensino-aprendizagem de Física. Também ajuda para a compreensão do conteúdo pelo aluno surdo e a abordagem realizada pelo educador.

O Celestia, contudo, não demonstrou muitas eficiências em sua interface, pois, em diversos momentos, o programa falhou ao receber determinados comandos. Isso impediu a visualização de alguns fenômenos e desmotivou os participantes. Assim, optamos por, na continuidade de nossas investigações, não utilizar esse instrumento como recurso tecnológico em potencial. É sempre importante que o educador tenha um olhar crítico sobre as mídias em educação para que sejam ferramentas facilitadoras do processo.

Quanto à educação de surdos, é evidente que há grande necessidade e um dever do docente em conhecer sobre a língua e a cultura surda, como forma de se aproximar do aluno surdo e de potencializar o diálogo e a interação. Além disso, ficou explícita a 
importância de se investir na capacitação de intérpretes de Libras no que diz respeito à alfabetização científica e tecnológica, bem como na formação de professores para o reconhecimento a respeito da cultura surda e Libras.

O uso de estratégias diferenciadas, como a adaptação e criação de sinais e o conhecimento da Libras e da cultura surda, aliadas às tecnologias e outros recursos visuais, demonstraram-se promissores, segundo as observações dos participantes. Consideramos que houve uma aproximação entre a Astronomia em Libras e TDIC com a cultura surda.

Esses recursos possibilitam que o aluno participe da aula não apenas presente no ambiente, mas interagindo com igualdade. Essa é uma das principais características a serem repensadas e investigadas para a verdadeira integração e inclusão dos sujeitos surdos tanto em escolas inclusivas bilíngues quanto na sociedade em sua totalidade.

Sabemos dos atrasos na aprendizagem dos sujeitos em razão de um sistema social e educacional ainda falho e da falta ou do pouco conhecimento da língua e da cultura surda no contexto familiar e escolar quando composto por uma maioria ouvinte. Do mesmo modo, pela descriminação e isolamento social, entre outros aspectos, é imprescindível reconhecer e investir nos direitos que indivíduos surdos têm de conhecer a ciência e de fazer parte dela, pois a ciência foi construída por todos e é para todos.

Com o minicurso mostramos que o ensino-aprendizagem de Astronomia em Libras, articulada às TDICs, é possível quando nos permitimos reconhecer a cultura e a língua, e os artefatos tecnológicos aproximam-se e contribuem na educação dos surdos.

Neste caso, enfatizamos que a Ciência é uma construção humana, colaborativa, política e histórica, não um privilégio para poucos, devendo, assim, ser acessível para todas as pessoas.

\section{REFERÊNCIAS}

ALMEIDA, M. E. B. de; SILVA, M. G. M. Da. Currículo, tecnologia e cultura digital: Espaços e tempos de web currículo. Revistae-curriculum, São Paulo: Pontifícia Universidade Católica de São Paulo, v. 7, n. 1, 2011. ARANY-PRADO, L. I. À luz das estrelas. São Paulo: DP\&A, 2017.

ARTUSO, A. R. O uso da hipermídia no ensino de física: possibilidades de uma aprendizagem significativa. 2006. Dissertação (Mestrado em Educação) - Programa de Pós-Graduação em Educação, Universidade Federal do Paraná, Curitiba, 2006.

BARDIN, L. Análise de conteúdo. São Paulo: Edições 70, 2011.

BRASIL. Constituição da República Federativa do Brasil, 1988.

BRASIL. Declaração de Salamanca: Sobre princípios, política e práticas na área das necessidades educativas especiais, 1994.

BRASIL. Decreto no 5.626, de 22 de dezembro de 2005 que dispõe sobre a Língua Brasileira de Sinais - Libras, 2005.

BRASIL. Lei no 10.436, de 24 de abril de 2002. Dispõe sobre a Língua Brasileira de Sinais - Libras e dá outras providências, 2002.

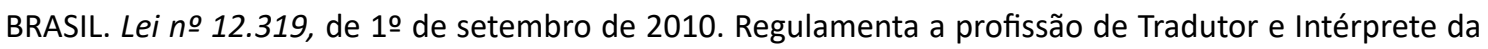
Língua Brasileira de Sinais - Libras, 2010.

BRASIL. Parâmetros Curriculares Nacionais Ensino Médio. Parte III - Ciências da Natureza, Matemática e suas Tecnologias, 2000.

BRASIL. Secretaria de Educação Fundamental. Parâmetros Curriculares Nacionais: Ciências Naturais. Brasília: MEC; SEF, 1998.

BRITO, L. F. Integração Social e Educação de Surdos. Rio de Janeiro: Babel, 1993. 
ESPÍNDOLA, M. B. Integração de tecnologias de informação e comunicação no Ensino Superior: análise das experiências de professores das áreas de ciências e da saúde com o uso da ferramenta Constructore. 2010. Tese (Doutorado em Educação), Difusão e Gestão em Biociências, Universidade Federal do Rio de Janeiro, Rio de Janeiro. 2010.

GOLDFELD, M. A criança surda: linguagem e cognição numa perspectiva sociointeracionista. Front Cover. São Paulo: Plexus Editora, 1997.

HORVATH, J. E. O ABCD da Astronomia e Astrofísica. São Paulo: Ed Livraria da Física, 2008.

KEPLER, S. O.; SARAIVA, M. de F. O. Astronomia e Astrofísica. Porto Alegre: Departamento de Astronomia; Instituto de Física Universidade Federal do Rio Grande do Sul, 20 jan. 2014.

LANGHI, R.; NARDI, R. Ensino da astronomia no Brasil: educação formal, informal, não formal e divulgação científica. Revista Brasileira de Ensino de Física, v. 31, n. 4, p. 4.402, 2009.

LANGHI, R.; NARDI, R. Justificativas para o ensino de Astronomia: o que dizem os pesquisadores brasileiros? Revista Brasileira de Pesquisa em Educação em Ciências, vol. 14, n. 3, 2014.

LEONEL, A. A. A utilização de um Blog para o ensino-aprendizagem de física: possibilidades para fortalecer a interação e potencializar a alfabetização científica e técnica. SIMPÓSIO NACIONAL DE ENSINO DE FÍSICA, SNEF, 20., 2013. São Paulo. Anais [...]. São Paulo, 2013.

LEONEL, A. A. Formação continuada de professores de física em exercício na rede pública estadual de Santa Catarina: lançando um novo olhar sobre a prática. 2015. Tese (Doutorado) - Universidade Federal de Santa Catarina, Florianópolis, 2015.

LÉVY, P. O que é virtual? Trad. Paulo Neves. São Paulo: Ed. 34, 1996.

LÜDKE, M.; ANDRÉ, M. E. D. A. Pesquisa em educação: abordagens qualitativas. São Paulo: E.P.U., 1986. MAIA, F.; MENDONÇA, L.; STRUCHINER, M. Blogs e ensino de Ciências: um estudo exploratório. ENCONTRO NACIONAL DE PESQUISA EM ENSINO DE CIÊNCIAS, 6., 2007, Florianópolis. Anais [...] Florianópolis: Enpec, 2007.

MENEZES, D. P. de.; CARDOSO, T. F. L. Planetário da gávea: ampliando a visão cosmológica de alunos surdos. SIMPÓSIO NACIONAL DE ENSINO DE FÍSICA - SNEF, 19., 2011, Manaus, AM. Disponível em: http:// www.sbf1.sbfisica.org.br/eventos/snef/xix/sys/resumos/T0678-1.pdf. Acesso em: 30 set. 2016.

MORAN, J. M.; MASETTO, M. T.; BEHRENS, M. A. Novas tecnologias e mediação pedagógica. 3 ed. Campinas: Papirus, 2001.

NOGUEIRA, J. B. G. C. S. Astronomia: Ensino Fundamental e Médio. Brasília: MEC; SEB; MCT; AEB, 2009. (Coleção explorando o ensino).

NUNES, M. R. Possibilidades e desafios no ensino de Astronomia pela Língua Brasileira de Sinais. 2017. Dissertação (Mestrado em Ensino de Astronomia) - Universidade de São Paulo, Instituto de Astronomia, Geofísica e Ciências Atmosféricas, Departamento de Astronomia, São Paulo, 2017.

OLIVEIRA, W. D. de.; BENITE, A. M. C. Aulas de ciências para surdos: estudos sobre a produção do discurso de intérpretes de Libras e professores de ciências. Revista Ciência e Educação, Bauru, v. 21, n. 2, p. 457472, jun. 2015. ISSN 1516-7313.

PASSERO, T.; BOTAN, E.; CARDOSO, F. C. O desenvolvimento de pesquisas sobre ensino de Física em Libras realizadas pelo grupo de estudo e pesquisa em educação de surdos Édouard Houet. SIMPÓSIO NACIONAL DE ENSINO DE FÍSICA - SNEF, 19., 2011, Manaus, AM, 2011. Disponível em: http://www.sbf1.sbfisica.org. br/eventos/snef/xix/sys/resumos/T0297-1.pdf. Acesso em: 18 set. 2016.

PERLIN, G. T. O lugar da cultura surda. In: THOMA, A. da S.; LOPES, M. C. (org.). A invenção da surdez: cultura, alteridade, identidades e diferença no campo da educação. Santa Cruz do Sul: Edunisc, 2004.

QUADROS, R. M. de. O tradutor e intérprete de Língua Brasileira de Sinais e Língua Portuguesa. 2. ed. Brasília: MEC; Secretaria de Educação Especial - SEESP, 2004.

QUADROS, R. M. Estudos de surdos III. Petrópolis, RJ: Editora Arara Azul, 2008.

QUADROS, R. M. de; PERLIN, G. T. Estudos Surdos II. Petrópolis, RJ: Editora Arara Azul, 2007.

SANTOS ROSA, S.; LEONEL, A. A.; ROSA, V. Modelos pedagógicos de EaD: contribuições com a literacia digital de professores em formação. CONGRESSO BRASILEIRO DE ENSINO A DISTÂNCIA, ESUD, 1., 2014, Florianópolis. Anais [...] Florianópolis: Nute-UFSC, 2014. p. 228-243. V. 1.

SANTOS, E. M.; ANDRADE, J. O.; SANTOS, N. O.; VIANA-BARBOSA, C. J. Inclusão e o ensino de Física: uma proposta de criar sinais no Ensino da Astronomia. SIMPÓSIO NACIONAL DE ENSINO DE FÍSICA - SNEF, 20., 2013, São Paulo, SP, 20 a 25 de janeiro de 2013. Disponível em: http://www.sbf1.sbfisica.org.br/eventos/ snef/xx/sys/resumos/T0016-2.pdf. Acesso em: 15 set. 2017. 
SANTOS, J. V. A.; LEONEL, A. A.; SCHWEDER, S. Uso de blogues: um meio para promover a alfabetização científica e técnica. CONGRESSO BRASILEIRO DE ENSINO SUPERIOR A DISTÂNCIA, ESUD, 10., 2013, Belém. Anais [...].Belém//PA: Esud, 2013.

SILUK, A. C. P. Formação de professores para o atendimento educacional especializado. Santa Maria: Universidade Federal de Santa Maria, 2012.

SKLIAR, C. Uma perspectiva sócio-histórica sobre a psicologia e a educação dos surdos. In: SKLIAR, C. (org.). Educação e exclusão: abordagens socioantropológicas em educação especial. Porto Alegre: Mediação, 1997.

STROBEL, K. As imagens do outro sobre a cultura surda. 4. ed. Florianópolis: UFSC, 2016.

STUMPF, M. R. Mudanças estruturais para a uma Inclusão Ética. In: QUADROS, R. M. de. Estudos de surdos III. Petrópolis, RJ: Editora Arara Azul, 2008.

VARGAS, J. S.; GOBARA, S. T. Sinais de libras elaborados para os conceitos de massa, força e aceleração. Polyphonía, v. 26/2, jul./dez. 2015a. Disponível em: https://www.revistas.ufg.br/sv/article/viewFile/38310/19414. Acesso em: 30 out. 2017.

VARGAS, J. S.; GOBARA, S. T. Sinais dos conceitos de massa, aceleração e força para surdos na literatura nacional e internacional. ENCONTRO NACIONAL DE PESQUISA EM EDUCAÇÃO EM CIÊNCIAS - ENPEC, 9., 2013, Águas de Lindoia, SP. Atas [...]. 10 a 14 nov. 2013. Disponível em: http://www.nutes.ufrj.br/abrapec/ixenpec/atas/resumos/R0186-1.pdf. Acesso em: 2 nov. 2017.

VARGAS, J. S.; GOBARA, S. T. Sinais de Libras para os conceitos de massa e aceleração: testagem e aceitação dos alunos surdos. SIMPÓSIO NACIONAL DE ENSINO DE FÍSICA - SNEF, 21., Uberlândia, MG - 26 a 30 jan. 2015b. Disponível em: http://www.sbf1.sbfisica.org.br/eventos/snef/xxi/sys/resumos/T0930-1.pdf. Acesso em: 6 nov. 2017.

VIVIAN, E. C.; LEONEL, A. A. Ensino de Astronomia para a educação de crianças surdas e deficientes auditivos na perspectiva de um Intérprete de Libras. SIMPÓSIO NACIONAL DE ENSINO DE FÍSICA - SNEF, 22., 2017, São Carlos, SP. Disponível em: http://www1.sbfisica.org.br/eventos/snef/xxii/sys/resumos/T07951.pdf. Acesso em: 2 dez. 2017. 